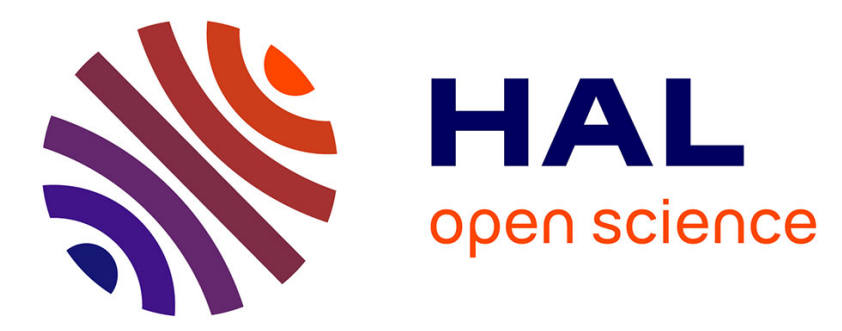

\title{
Creating a Regional and Historical Streetscape Simulation System \\ Yasuo Kawai
}

\section{To cite this version:}

Yasuo Kawai. Creating a Regional and Historical Streetscape Simulation System. 16th International Conference on Entertainment Computing (ICEC), Sep 2017, Tsukuba City, Japan. pp.456-459, 10.1007/978-3-319-66715-7_62 . hal-01771263

\section{HAL Id: hal-01771263 \\ https://hal.inria.fr/hal-01771263}

Submitted on 19 Apr 2018

HAL is a multi-disciplinary open access archive for the deposit and dissemination of scientific research documents, whether they are published or not. The documents may come from teaching and research institutions in France or abroad, or from public or private research centers.
L'archive ouverte pluridisciplinaire HAL, est destinée au dépôt et à la diffusion de documents scientifiques de niveau recherche, publiés ou non, émanant des établissements d'enseignement et de recherche français ou étrangers, des laboratoires publics ou privés. 


\title{
Creating a Regional and Historical Streetscape Simulation System
}

\author{
Yasuo Kawai $^{1}$ \\ ${ }^{1}$ Bunkyo University, 1100 Namegaya, Chigasaki-city, Kanagawa 253-8550, Japan \\ kawai@shonan.bunkyo.ac.jp
}

\begin{abstract}
The purpose of this study is to create a streetscape simulation system to support local cultural succession by conveying - in a clear and simple waylocal history and culture to interested members of the public. We developed an interactive system, based on a game engine, for the streetscape of Fujisawa-juku, which is a post-station town on the former Tokaido Road of the late Edo period. We designed 3D models for former architecture and urban facilities, using Ukiyo-e and old documents provided by the Fujisawa city archive as references. In addition, regarding dynamic spatial elemental components that encourage users to visually survey the area, we prepared non-player characters that walk in a specified range and communicate a fixed set of remarks. Furthermore, we created soundscapes, which correspond to particular locations, using sound effects in the 3D models by incorporating natural sounds. The developed streetscape simulation system is on permanent exhibition at the Fujisawa-juku Intersection Hall and is widely accessible to the public.
\end{abstract}

Keywords: Streetscape Simulation • Game Engine • Post-station Town.

\section{$1 \quad$ Introduction}

In this study, we developed a simulation system that reproduces the historical and cultural landscape in order to transmit information and knowledge regarding a district's history and culture in a clear and simple way. Due to a variety of societal changes, such as urbanization, depopulation, declining fertility, and population aging, it is difficult to pass on regional history and culture in Japan. In 2007, the Agency for Cultural Affairs of Japan proposed the Basic Scheme for Historic and Cultural Properties to capture districts' cultural assets, regardless of designation or specification, in a comprehensive effort to preserve and use these assets as well as their surrounding environments.

Through our study of the development of an urban space simulation system using a game engine, we were able to modify the spatial component such that we could remove objects influencing the landscape and evaluate the remaining landscape image. Thus, in this study, we applied knowledge of this urban space simulation system to develop a simulation system that reproduces the historical cultural landscape in virtual space.

Previous studies have incorporated virtual reality technology in landscape simulation systems [1]. These systems, however, were typically developed for a dedicated 
application and, consequently, lack the versatility necessary for use in alternate locations. However, there are studies more relevant to our objective that focus on landscape simulation using game engines. Within these studies, several successfully developed simulation systems for historical sites [2, 3]. In fact, some systems were able to reproduce historical architecture; however, only a few studies developed their simulation systems to work on a town scale.

\section{Methods}

\subsection{Study Area}

The study area of this system was Fujisawa-juku (currently Fujisawa city, Kanagawa Prefecture), which is the sixth post-station town on the former Tokaido Road. Fujisawajuku flourished as the temple town of Shojoko-ji (Yugyo-ji) Temple, which is the grand head temple of the Ji-Shu sect, and was designated as one of the first post-station towns in 1601. In 1843, Fujisawa-juku contained one honjin (inn designated as an official lodging for a daimyo (great lord)), one waki honjin (subsidiary inn used by daimyo attendants), and 45 inns.

Based on Ukiyo-e (color prints of everyday life during the Edo period) and old documents, this study developed a schematic of Fujisawa-juku during the late Edo period. In this system, we reproduced the area around the Daigiri Bridge over the Sakai River from Shojoko-ji Temple in the northeastern part to Maita honjin in the west (Fig.1.).

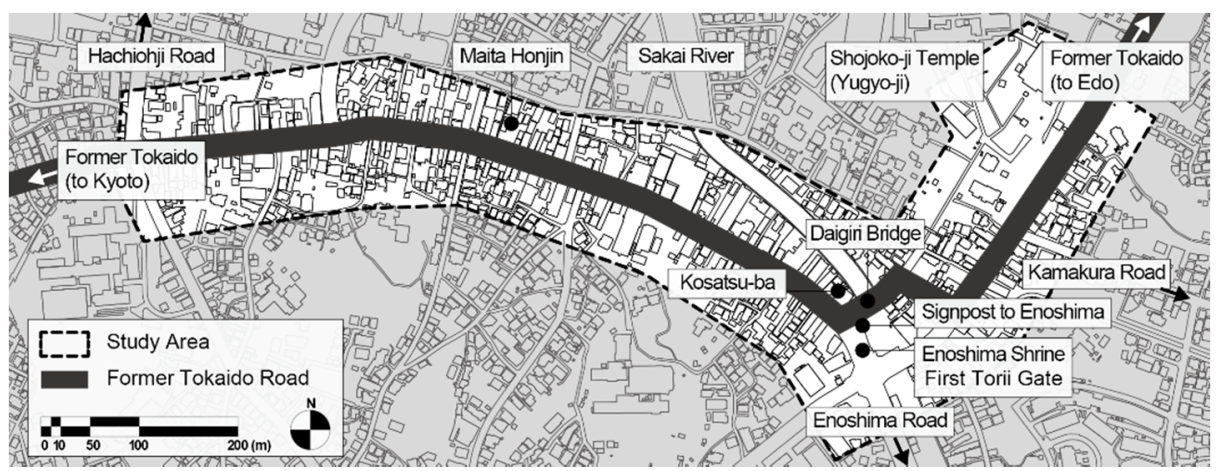

Fig. 1. Fujisawa-juku that was the post-station town on Former Tokaido Road

\subsection{Development}

To develop our simulation system, we used a game engine called Unreal Engine. We decided to create a model of individual spatial components in the three-dimensional computer graphics production environment and to incorporate texture map and normal map in image format into the game engine. We designed 3D models for architectural structures, such as the temple, honjin, waki-honjin, inns, merchant houses, and urban 
facilities, such as torii (gateway entrance to an Enoshima shrine), kosatsu-ba (street bulletin board), bridges, trees, plants, and so on.

In addition, regarding dynamic spatial elemental components that encourage users to visually survey the area, we prepared non-player characters (NPC) that walk in a specified range and communicate a fixed set of remarks to coincide. To reproduce the streetscape with friendly feeling, we arranged NPC models based on the behaviors of the people who lived in Fujisawa-juku, such as tradesmen, Buddhist monks, meshimorionna (maid at an inn), as well as the visitors to the post-station town, such as samurai and travelers. Furthermore, we created soundscapes, which correspond to particular locations, using sound effects in the 3D models by incorporating natural sounds, such as the river flowing, birds singing, and insects chirping.

\subsection{Interface}

We designed the system to be interactive so that we could freely move in the poststation town. The operational method of the first-person perspective is to move the point of view using the keyboard and to rotate the line of sight using the mouse. When it is released to the public, it will be easy to operate using a gamepad. In this operational method, movement by the left analog pad and rotation by the right analog pad are set as the basic operating methods. Furthermore, various activities, such as jumping, respawning (moving to preset position), horse riding, and saisen (offering of money to temples), are offered, and several keys and buttons were assigned to these activities in each interface. For the gamepad, we decided to match activities to conditions (Fig.2).

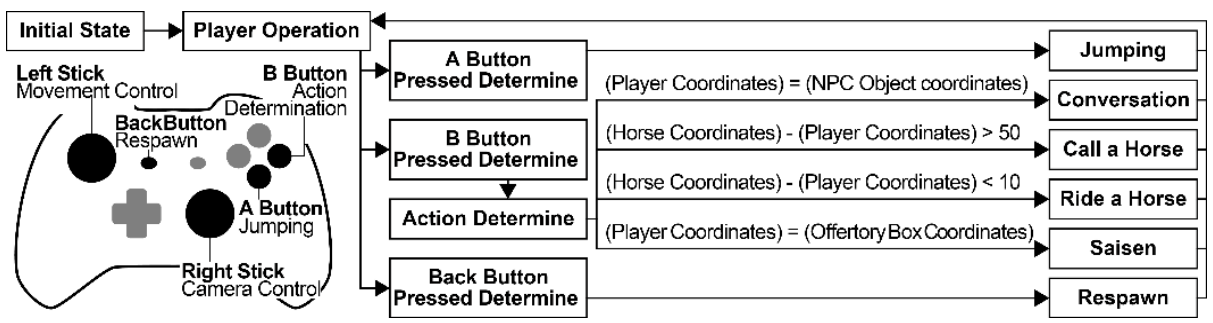

Fig. 2. Basic operation method of game pad and processing of activities by button actions.

\section{$3 \quad$ Results and Discussion}

The developed streetscape simulation system is on permanent display at the Fujisawajuku Intersection Hall and is widely accessible to the public (Fig.3.). The public exhibition is displayed on a 40-inch monitor connected to a PC controlled with a gamepad. This is an independent system not connected to a network, and, by automatically launching the executable file when the computer is booted up, it is set so that even curators unfamiliar with the system could operate it with ease. There are no major problems in its current operation and it functions stably. After opening the public exhibition, we received some user suggestions with which we could improve the system. For example, certain spatial elements visually expressed in Ukiyo-e were deformed, and a few 
elements, such as the Enoshima signpost, allegedly differed from the actual shapes of the past. Therefore, to assess these matters, we referenced old documents provided by the Fujisawa city archive. In the future, we will increase the accuracy of this system through comparisons with a variety of literature and user evaluations.

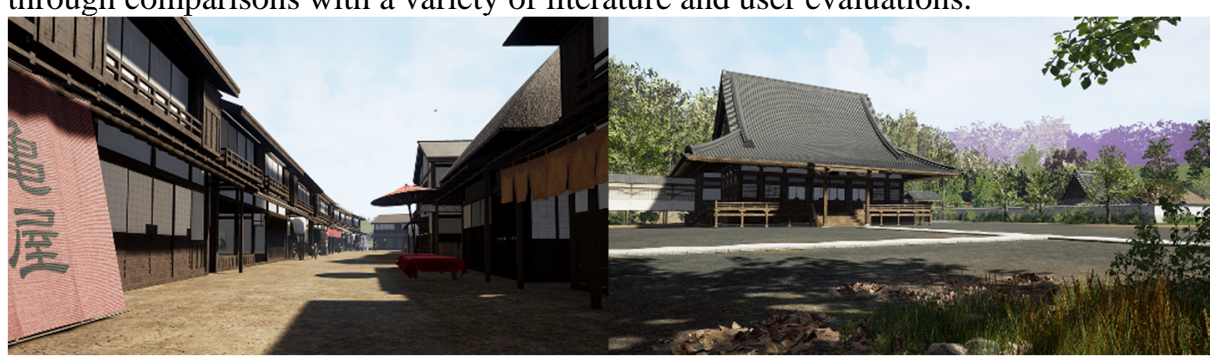

Fig. 3. Operation screen of proposed system, the left side shows the Former Tokaido Road, while the right side shows the precincts of the Shojoko-ji (Yugyo-ji) Temple.

\section{Conclusions}

The purpose of this study was to develop a system to support local cultural succession by conveying—in a clear and simple way—-the Fujisawa-juku of the late Edo period to members of the public interested in the local history and culture. Currently, the system comprises the Yugyo-ji Temple across the Daigiri Bridge to the area leading to Maita honjin. In the future, we plan to update the contents, which will expand the system to cover the entire town of Fujisawa-juku, address the feedback obtained from the public exhibition, and improve the system to be a post-station town streetscape simulation system that is as realistic as possible. Furthermore, based on the findings obtained with this system, we plan to convert it to general application and develop a platform for a historical cultural landscape simulation system that can be used in other areas.

\section{Acknowledgment}

This work was supported by JSPS KAKENHI Grant Number JP16K00718.

\section{References}

1. Santosa, H., Ikaruga, S., \& Kobayashi, T.: Development of Landscape Planning Support System using Interactive 3d Visualization: A case study in Malang, Indonesia. Journal of Architecture and Planning, 79 (706), 2699-2709 (2014).

2. Fukuda, T., Ban, H., Yagi, K., \& Nishiie, J.: Development of High-Definition Virtual Reality for Historical Architectural and Urban Digital Reconstruction. In Celani, G., Sperling, D. M., \& Franco, J. M. S. (eds.): 16th International Conference, CAAD Futures 2015, LNCS, vol.527, pp.75-89. Berlin Heidelberg: Springer-Verlag (2015).

3. Sheng, W., Ishikawa, K., Tanaka, H. T., Tsukamoto, A., \& Tanaka, S.: Photorealistic VR space reproductions of historical kyoto sites based on a next-generation 3D game engine. Journal of Advanced Simulation in Science and Engineering 1(1), 188-204. (2015). 